九州大学学術情報リポジトリ

Kyushu University Institutional Repository

\title{
Developments of Coal-Fired Power Plants: Microscopy Study of Fe-Ni Based Heat-Resistant Alloy for Efficiency Improvement
}

Akamine, Hiroshi

Department of Applied Science for Electronics and Materials, Interdisciplinary Graduate School of Engineering Sciences, Kyushu University

Mitsuhara, Masatoshi

Department of Engineering Sciences for Electronics and Materials, Faculty of Engineering Sciences, Kyushu University

Nishida, Minoru

Department of Engineering Sciences for Electronics and Materials, Faculty of Engineering Sciences, Kyushu University

https://doi.org/10.5109/1800871

出版情報: Evergreen. 3 (2)，pp.45-53，2016-09. Green Asia Education Center バージョン：

権利関係 : 


\title{
Developments of C oal-Fired Power Plants: Microscopy Study of Fe-Ni Based Heat-R esistant Alloy for E fficiency Improvement
}

\author{
Hiroshi Akamine ${ }^{1,}$, Masatoshi Mitsuhara ${ }^{2}$, Minoru Nishida ${ }^{3}$ \\ ${ }^{1}$ Department of Applied Science for Electronics and Materials, Interdisciplinary Graduate School of \\ Engineering Sciences, K yushu University, Kasuga 816-8580, Japan \\ ${ }^{2}$ Department of Engineering Sciences for Electronics and $M$ aterials, Faculty of Engineering \\ Sciences, Kyushu University, Kasuga 816-8580, Japan \\ *Author to whom correspondence should be addressed, \\ E-mail: 3ES14001R@s.kyushu-u.ac.jp
}

(Received A ugust 1, 2016; accepted September 21, 2016)

\begin{abstract}
Anthropogenic emissions of greenhouse gases are one of the possible reasons for the global warming. Coal consumption is predicted to be increased over several decades due to increasing demands in some countries. In the medium-term energy strategy, coal-fired power plants thus need to be developed. For this purpose, developments of new heat-resistant alloys that can stand severe steam conditions in advanced power plants are essential. A potential alloy was studied, which revealed that hardness of the alloy is related to the distribution of precipitates. The development of the alloy is al so vital to make the power plants more economically competitive.
\end{abstract}

Keywords: global warming, coal-fired power plants, heat-resistant alloy, electron microscopy

\section{Introduction}

Global warming is one of the major climate changes, which represents a gradual increase of the global mean temperature mainly due to greenhouse gases $(\mathrm{GHG})$, such as carbon dioxide $\left(\mathrm{CO}_{2}\right)$, methane $\left(\mathrm{CH}_{4}\right)$, nitrous oxide $\left(\mathrm{N}_{2} \mathrm{O}\right)$, ozone $\left(\mathrm{O}_{3}\right)$, and chlorofluorocarbons (CFCS). Since disastrous secondary issues, such as an elevation of the sea level, are subject to the increase of the global mean temperature, the global warming has been a crucial problem. Intergovernmental Panel on Climate Change (IPCC) has reported in its fifth report ${ }^{1)}$ that there is no doubt that global warming is actually in progress and there is a clear positive correlation between the increasing global mean temperature and the total amount of anthropogenic emissions of GHG. The reduction of GHG emissions is therefore urgent to suppress the global warming, although there are several reports which argue that the increase of global mean temperature is not artificial, but a natural event as a part of the long-term variation of the global mean temperature ${ }^{2)}$. Discussions in this article will be addressed from the former standpoint, i.e we are positive on the occurrence of the global warming.

In order to suppress GHG emissions, an international framework, the K yoto Protocol, was adopted in 1997 and entered into force in 2005. In the Kyoto Protocol, reduction targets of GHG emissions are imposed to developed countries, whereas the first two of the most emitting countries, China and U.S., were not included. Although the significance of the Kyoto Protocol is limited due to the absence of China and U.S., the K yoto Protocol provided an opportunity to establish a novel, market mechanism as an alternative measure to achieve the reduction target, which is referred to as the Kyoto $M$ echanisms. In the climate conference in Copenhagen in 2009, the world's government agreed to limit global mean temperature change to below $2{ }^{\circ} \mathrm{C}$ compared with pre-industrial levels (the Copenhagen A ccord). Despite a lack of scientific assessments on the value ${ }^{3)}$, this agreement has encouraged each country to take appropriate actions to tackle the global warming. A subsequent international framework, the Paris Accord, was adopted in Paris on 12 December 2015. A noteworthy achievement is that 196 countries and regions including China and U.S. agreed on this accord ${ }^{4}$.

The developments of the international framework for cutting GHG emissions have induced considerable changes in energy policies of all related countries. Owing to the introduction of the market mechanism to GHG emissions management, it became essential to incorporate additional cost that is assigned to extra GHG emissions. M ore importantly, world-wide movements to support renewable energies have helped approvals of new rules and laws in developed countries, which, for example, regulate constructions of a new fossil-fuel 
Table1Estimated life-cycle $\mathrm{CO}_{2}$ emissions in each power generator $\left(\mathrm{g}-\mathrm{CO}_{2} / \mathrm{kWh}\right)^{9)}$. Direct emission is originated from fossil fuel combustions.

\begin{tabular}{cccccccccc}
\hline & Wind & Solar & Geothermal & Hydropower & Nuclear & $\begin{array}{c}\text { LNG } \\
\text { (combined) }\end{array}$ & $\begin{array}{c}\text { LNG } \\
\text { (steam) }\end{array}$ & Oil & Coal \\
\hline Direct & 0 & 0 & 0 & 0 & 0 & 376 & 476 & 695 & 864 \\
Indirect & 25 & 38 & 13 & 11 & 20 & 98 & 123 & 43 & 79 \\
\hline Total & 25 & 38 & 13 & 11 & 20 & 474 & 599 & 738 & 943 \\
\hline
\end{tabular}

power plant ${ }^{5}$ or provide subsidies to renewables-based systems ${ }^{6}$. . These have contributed to increasing investments on renewable energies, resulting in increasing share of renewable energies in several countries. These actions, however, are often inclined to environmental conservation and paying fewer attentions to other factors such as energy security. Practically, an energy policy should be dependent on several factors; e.g. (1) environmental conservation, which have been al ready taken into account as described above; (2) economic competitiveness; and (3) energy security. The factors (2) and (3) will be discussed in the section 2 .

Coal-fired power plants have been the most popular systems for many countries to stably provide inexpensive electric powers to industrial and residential purposes, since the coal has rich recoverable reserve and thus can be obtained inexpensively. Additionally, the coal is distributed over many countries and regions, whereas other fossil fuels, oil and natural gas, are localized in limited areas (e.g. in Middle Eastern countries, China, Russia, and U.S. $)^{7)}$. In terms of energy security, the biased distribution of the resource is a potential risk due to unexpected resource nationalism that could threaten stable procurements of the resource, although the situation is being gradually improved due to the recent emergence of the Shale oil and gas in U.S. and other countries ${ }^{8)}$. A ccordingly, the coal has been preferred as a secure resource.

Coal-fired power plants, however, has been a major source of GHG. For simplicity, we will focus only on $\mathrm{CO}_{2}$ emissions hereafter. In fact, it has been reported that the life-cycle $\mathrm{CO}_{2}$ emissions of coal-fired power plants are estimated as $943 \mathrm{~g}-\mathrm{CO}_{2} / \mathrm{kW} \mathrm{h}$ that is larger than other systems $(\text { Table } 1)^{9)}$. Note that the life-cycle $\mathrm{CO}_{2}$ emissions are assessed by dividing the total $\mathrm{CO}_{2}$ emissions in all related processes, including construction and management of the power plant, transportation and fabrication of the coal, etc., by the total energy that is generated during the whole working time of the power plant (i.e from the first activation to the retire) (see Ref. 9 for the detail). Although the emissions are very small for nuclear and renewable energy, many of the nuclear power plants are currently difficult to be activated after the accidents of the Fukushima nuclear power plants in 2011, and the renewables still have many difficulties that need to be resolved such as high management cost and instability due to their whether-dependence. The developments of high-efficiency (low- $\mathrm{CO}_{2}$ emission) coal-fired power plants are thus indispensable to achieve both stable energy supply and low $\mathrm{CO}_{2}$ emission.

In the next section, the role of advanced coal-fired power plants in Japan will be discussed. This derives that in medium-term energy strategy, a mixed system consisting of multiple types of power plants is useful to achieve both sufficient energy security and low $\mathrm{CO}_{2}$ emissions. The third section of this article firstly describes an overview of advanced coal-fired power plants, in which we emphasize that developing heat-resistant alloys is essential to establish advanced high-efficiency coal-fired power plants. A Iso, we explain a metallurgical strategy to improve the mechanical properties of heat-resistant alloys, through a materials science and engineering studies on one of the potential heat-resistant alloys. In these studies, we evaluate microstructures of the alloy using electron microscopy and discuss the relation between the mechanical properties and microstructures. The results include a technological insight for the further development of the alloy.

\section{Role of the advanced coal-fired power plants in the energy strategy}

In this section, we shall discuss the role of advanced coal-fired power plants in Japan in terms of economic competitiveness and energy security. Reserves of the coal are distributed over a wide regions and countries: It has been reported that $27.6 \%$ of recoverable reserves of the coal is located in U.S., $18.2 \%$ in Russia, $17.1 \%$ in European regions, $13.3 \%$ in China, $8.9 \%$ in Australia, $7.0 \%$ in India, and $7.9 \%$ in other countries in 201010), and notably $74.3 \%$ of the coal in Japan was imported from A ustralia, $12.9 \%$ from Indonesia, $8.7 \%$ from Russia, and $4 \%$ from other countries in 201411). The unbiased distribution is thus an advantage for Japan to avoid geopolitical risks and stably supply the resource to domestic consumers. In addition, the world reserve-production ratio of the coal, which is a rough estimate of how many years the production of the resource can sustain, marked 114 in 2016 and the value has shown increasing trend since 2014, whereas that of the natural gas is 54.48 with decreasing trend $d^{7}$. The coal is accordingly more reasonable resource than other fossil 


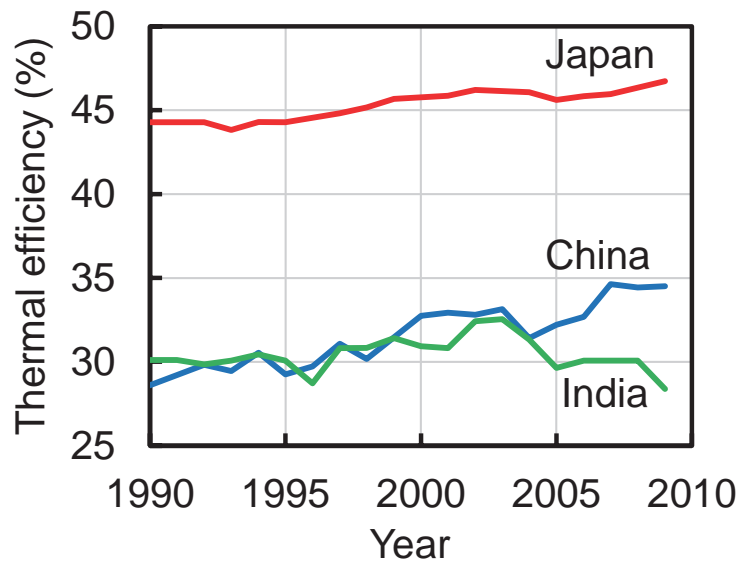

Fig 1 Developments of gross thermal efficiency of coal-fired power plants in selected three countries ${ }^{13)}$. The gross efficiency represents only an efficiency of the thermal cycle, not including the energy consumption for running the power plant.

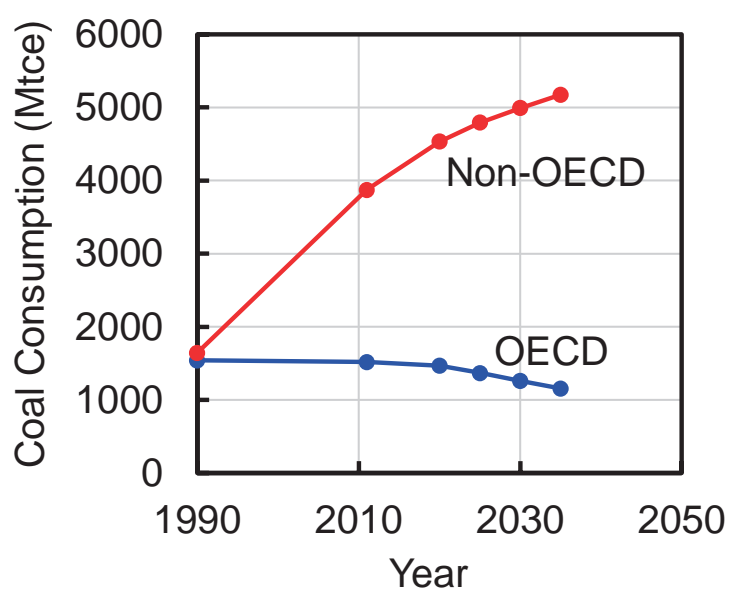

Fig. 2 Prediction of coal consumption in OECD countries (blue line) and non-OECD countries (red line), where the values in 1990 and 2011 are the measured data ${ }^{17)}$.

fuels, as far as the distribution and the amount of the recoverable reserve are concerned.

Technological advancements in coal-fired power plants can enhance the economic competitiveness. The efficiency of coal-fired power plants in Japan has been continuously improved ${ }^{12)}$. The thermal efficiency of coal-fired power plants in Japan has continuously marked high compared with that in other countries that have major consumptions of the coal as shown in Fig. 1. Figure 1 describes the time-development of gross thermal efficiency of Japan, China, and India ${ }^{13)}$, which are calculated by using input and output energies in coal-fired power plants of each country. The difference is because China and India have faced a shortage of electric power supply due to increasing industrial scale, inappropriate policy, etc. ${ }^{14,15)}$ The situation is also the same for some other countries ${ }^{16)}$, and all of those countries have relied on low-costed power plants at the expense of efficiency to deal with electricity deficit. These facts indicate that there are opportunities to export the advanced high-efficiency systems to those countries. Similarly, it is predicted by International Energy A gency (IEA) that the coal consumption in non-OECD (Organization for Economic Co-operation and Development) countries, including China and India, will be increased over at least several decades (Fig. 2) ${ }^{17)}$. The trading of the high-efficiency power plants thus can give benefits to both exporting and importing countries through the trading mechanism of GHG emissions. IEA predicted the world-averaged thermal efficiency of coal-fired power plants will be $37 \%$ in $2030^{18)}$. Since the thermal efficiency of advanced coal-fired power plants reaches $46 \%$ as mentioned later, updating the current power plants is significantly effective for reducing $\mathrm{CO}_{2}$ emission. For instance, it is estimated that the replacement of half of coal-fired power plants by the advanced ones reduces $\mathrm{CO}_{2}$ emission by 1.4 billion tons per year ${ }^{19}$. In fact, J apanese government has regarded exportations of the infrastructures, including advanced coal-fired power plants, as one of the main economic strategies $^{20)}$. For that purpose, it is vital to produce systems with higher efficiency and lower cost than those of the other competitors. We emphasize that both efficiency and introduction/management costs of the power plants can be improved by some methodologies: one of the promising ways is to develop new materials as addressed later.

Despite these advantages, the coal-fired power plants will be replaced by renewable energies ${ }^{21)}$. Since the renewables, in principle, require no import of resources and cause no direct GHG emissions (see Table 1), they are apparently future alternatives to the current power generation systems. However, it should be noted that the share of fossil-fuel power plants has been continuously increased across two decades, despite the increasing contribution of renewables ${ }^{17}$. This indicates that there are large, urgent demands of electricity that is superior to the reduction of $\mathrm{CO}_{2}$ emissions, particularly in the countries which are undergoing drastic economic growth as addressed earlier. A nother reason is because the current technologies of renewables still have many problems to be resolved, such as high introduction and management costs and a strong whether-dependence. The current systems of renewables thus need continuous supports from other power plants to keep a stable power supply. 
Table 2 Efficiency, steam temperature and pressure in each type of system.

\begin{tabular}{cccc}
\hline & $\begin{array}{c}\text { Efficiency } \\
(\% \mathrm{HHV})\end{array}$ & $\begin{array}{c}\text { Steam temperature } \\
\left({ }^{\circ} \mathrm{C}\right)\end{array}$ & $\begin{array}{c}\text { Steam pressure } \\
(\mathrm{M} \mathrm{Pa})\end{array}$ \\
\hline Subcritical $^{* 1}$ & 35.5 & 541 & 17.9 \\
Supercritical $^{* 1}$ & 38 & 582 & 26.2 \\
1100 SSC $^{* 1}$ & 40 & 604 & 27.6 \\
1300 A $_{\text {U SC }}{ }^{* 1}$ & 47 & 680 & 35.2 \\
A - USC $^{* 2}$ & $46 \sim 48$ & 700 & 35 \\
\hline
\end{tabular}

${ }^{* 1}$ Ref. $11,{ }^{* 2}$ Ref. 10

Table 3 Chemical composition of the specimen (wt.\%).

\begin{tabular}{ccccccccc}
\hline $\mathrm{Ni}$ & $\mathrm{C}$ & $\mathrm{Si}$ & $\mathrm{Mn}$ & $\mathrm{Cr}$ & $\mathrm{W}$ & $\mathrm{Ti}$ & $\mathrm{Nb}$ & $\mathrm{Fe}$ \\
\hline Bal. & 0.1 & 0.4 & 1.0 & 23 & 7.0 & 0.1 & 0.2 & 23 \\
\hline
\end{tabular}

In order to resolve the problems in renewables systems, extensive efforts have been made. High introduction and management costs have been compensated by subsidies from the government through the feed-in tariff sheme ${ }^{6}$. Although the subsidy has successfully increased the number of renewables systems, the share in domestic power supply still remains $4.7 \%$ in 201522). This indicates that further technological developments are essential for spreading renewables systems more widely. $M$ any of the problems are, however, still difficult to be overcome shortly. One of the important roles of advanced coal-fired power plants is therefore to support the conversion from the present systems to future renewables-based systems.

Consequently, advanced high-efficiency coal-fired power plants have large potentials to reduce $\mathrm{CO}_{2}$ emissions by means of replacing low-efficient power plants in developing countries. These demands provide business opportunities to export their systems to the other countries. Since the increase in coal demands is expected at least over several decades, fossil-fuel power plants including coal-fired power plants should play a primary role in medium-term energy strategy to support the gradual shift from the current systems to the future renewables-based systems.

\section{Developments of advanced coal-fired power plants and materials science and engineering studies on $\mathrm{Fe}-\mathrm{Ni}$ based heat-resistant alloy}

The coal-fired power plants have been updated and classified into sub critical (sub-C), super critical (SC), ultra super critical (USC), and advanced ultra super critical (A-USC) systems with reference to pressure and temperature conditions of the main steam $^{23)}$. The efficiency of a coal-fired power plant can be enhanced by increasing the steam pressure and temperature, since the available output work is increased by using higher steam pressure and temperature. The efficiency, steam temperature and pressure in each type of coal-fired

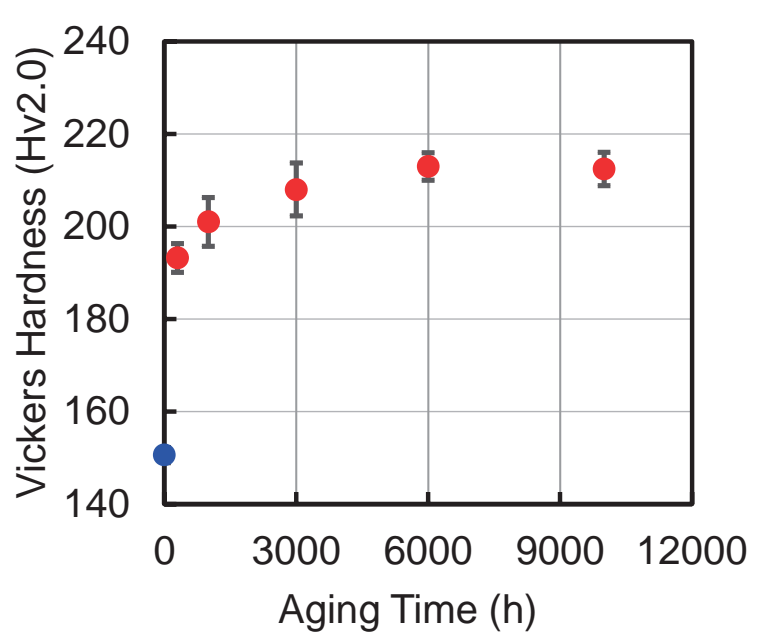

Fig. 3 Vickers hardness of solution-treated (blue dot) and aged (red dots) samples.

power plants are listed in Table 223,24). The A-USC system in Japan aims at using the main steam conditions of $35 \mathrm{M} \mathrm{Pa}$ and $700{ }^{\circ} \mathrm{C}$. For that purpose, it is essential to develop a new heat-resistant material that can keep high strength, durability, corrosion resistance, etc., over a long running period under the severe steam conditions of A-USC systems.

One of the potential materials is an $\mathrm{Fe}-\mathrm{Ni}$ based heat-resistant alloy that has well-balanced properties in terms of cost and mechanical properties ${ }^{25}$. In order to improve the mechanical properties of the alloy, we observed microstructures of four samples aged at $700{ }^{\circ} \mathrm{C}$ for $300,1000,6000$, and 10000 hours, respectively, after the solution treatment at $1220^{\circ} \mathrm{C}$.

The chemical compositions of the specimens are presented in Table 3. The mechanical property of the specimens was evaluated by the conventional Vickers hardness test. The drastic rise in hardness was observed in the initial stage of aging and the increasing rate was gradually diminished in the later stage (Fig. 3). To understand this behavior, we performed cross-sectional microstructure observations using a scanning electron 


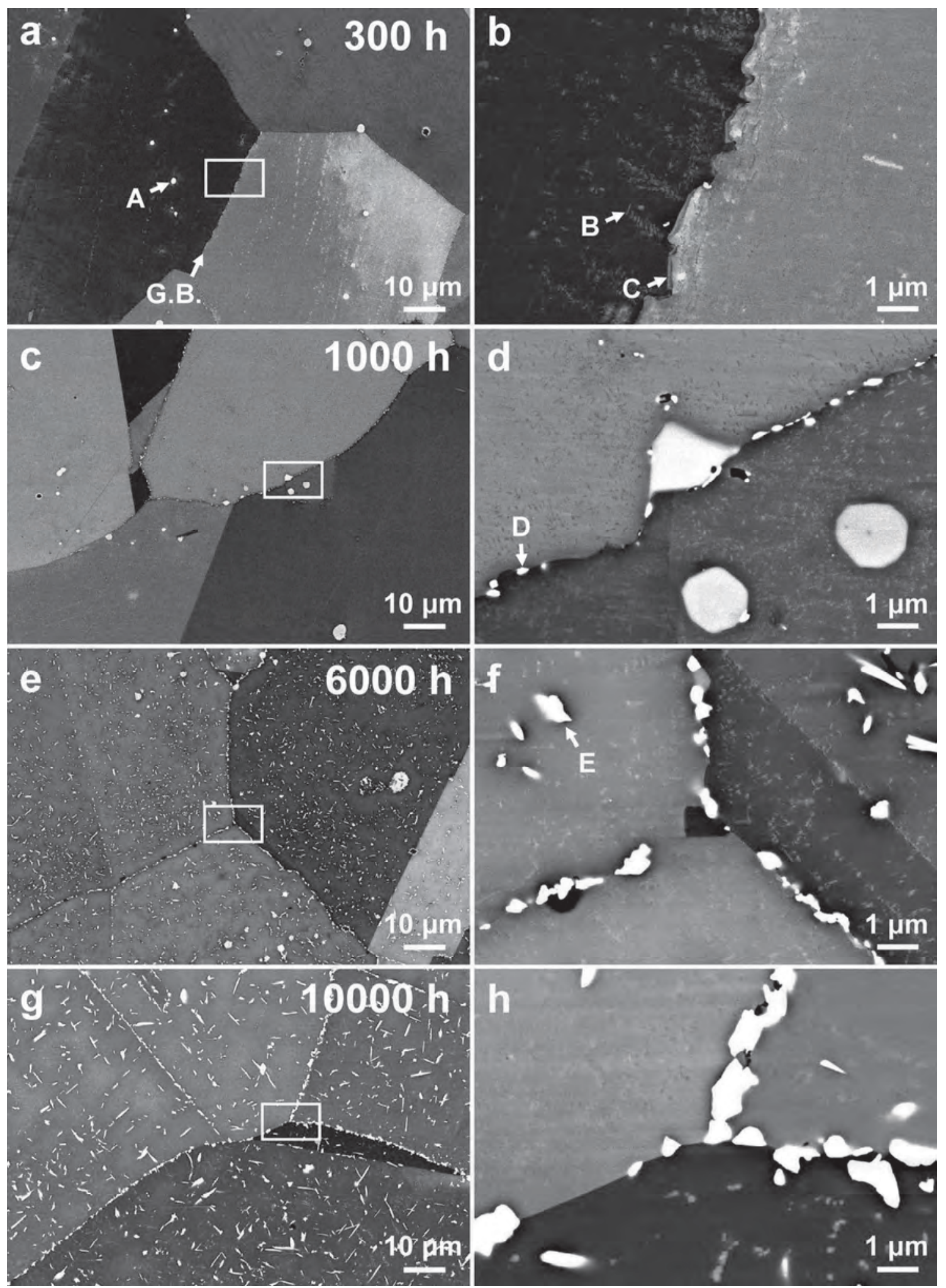

Fig $4(\mathrm{a}),(\mathrm{c}),(\mathrm{e})$, and (g) Low magnification cross-sectional SEM images of aged specimens. (b), (d), (f) and (h) Enlarged images of the regions indicated by white rectangles in (a), (c), (e) and (g), respectively. Each type of precipitates is denoted by arrows at their first appearance in the aging process. Note that precipitates are classified by contrast in the SEM images and their locations, i.e. inside the grains or on the grain boundaries.

microscope (Carl Zeiss, ULTRA55) and a transmission electron microscope (FEI, Titan $\left.{ }^{3}\right)$. The cross-sectional SEM specimens are prepared by mechanical and chemical polishing, and TEM specimens are prepared by electro polishing.

Figures 4a-g show cross-sectional SEM images of the 


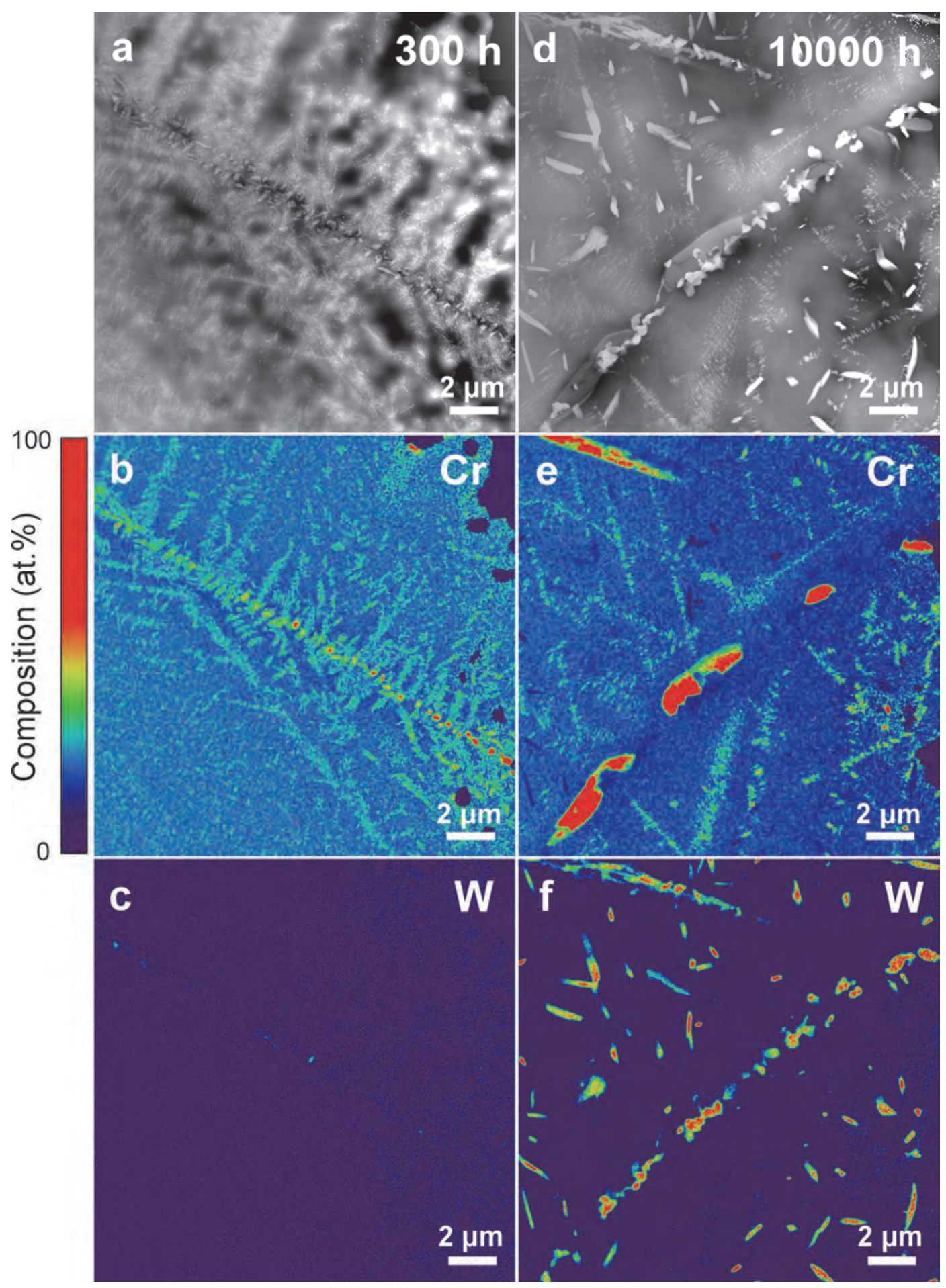

Fig 5 (a) Scanning transmission electron microscope image and (b), (c) quantified chemical composition map of $\mathrm{Cr}$ and $\mathrm{W}$ for the sample annealed for $300 \mathrm{~h}$. (d), (e), and (f) those for the specimen aged for $10000 \mathrm{~h}$.

specimens aged at $700{ }^{\circ} \mathrm{C}$, where the images in the right column are the enlargements of the regions in the left column denoted by white rectangles. Several types of precipitates are observed inside the crystal grains or on the grain boundaries, which are denoted as A, B, C, D, and $E$ with arrows at their first appearance in the annealing. Note that here the precipitates are classified based on their contrasts in the SEM images and positions, i.e. inside the grain or on the grain boundary. The precipitates at the grain interior (type A) in Fig. 4a are relatively large, and X-ray chemical composition analysis in SEM revealed that the precipitates are $\mathrm{Cr}$-rich $\mathrm{M}_{23} \mathrm{C}_{6}(\mathrm{M}=\mathrm{Ni}, \mathrm{Mn}, \mathrm{Cr}, \mathrm{W}, \mathrm{Ti}, \mathrm{Nb}, \mathrm{Fe}$ ) carbides that have been reported in a previous study ${ }^{26)}$. The type $B$ and $\mathrm{C}$ precipitates are also found to be $\mathrm{Cr}$-rich from the composition analysis in TEM (Figs. $5 b$ and $c$ ). Note that 
composition maps in Fig. 5 only displays $\mathrm{Cr}$ and $\mathrm{W}$ elements that comprises a major fraction of the precipitates. The type $\mathrm{C}$ precipitates disappears in the specimen aged for $1000 \mathrm{~h}$, and instead, another precipitates (type D) with bright contrast appears (Fig. 4d). Similar bright precipitates are observed inside the grains (type E) in the stage later than $6000 \mathrm{~h}$ (Figs. 4e-h). These type $D$ and $E$ precipitates are both found to be $\mathrm{Fe}_{2} \mathrm{~W}$-type $\mathrm{L}$ aves phase from the composition analysis in TEM (Figs. 5e and $f$ ) and the previous report ${ }^{27)}$. Additional TEM analysis on the crystal structure revealed that the fine precipitates at the grain interior (type $\mathrm{B}$ ) are $\mathrm{Cr}$-rich $\mathrm{M}_{23} \mathrm{C}_{6}$ carbides that have coherent lattice match with the cubic matrix structure (Figs. 6a-c). Since coherent interfaces always include elastic strains proportional to the lattice mismatch, and increases interfacial energy, the mean size of $\mathrm{M}_{23} \mathrm{C}_{6}$ carbides are kept fine over the long aging time, whereas $L$ aves phase are rapidly coarsened in the later stage of aging (see Fig. 2). The area fraction of the Laves phase clearly increases through the aging. On the other hand, a number of fine $\mathrm{M}_{23} \mathrm{C}_{6}$ carbides, which are slightly coarsened with increasing aging time, are continuously present inside the grains. These results indicate that the precipitation processes in the aged specimens is progressed with diffusional transformation toward the equilibrium state ${ }^{28)}$.

The secondary phase dispersed in the matrix phase enhance the mechanical properties of crystalline materials due to the prevention of dislocation motion ${ }^{29)}$. In general, the resistance force against the dislocation motion depends on the spacing between the precipitates. $W$ hen the mean spacing between the precipitates is $\lambda$, the stress to deform the alloy, $\sigma$, based on the Orowan mechanism is expressed by ${ }^{30)}$ :

$\sigma=\frac{2 \mathrm{~Gb}}{\lambda}$

where $G$ is the shear modulus of the alloy, and $b$ is the burgers vector of dislocations. It follows from the equation (1) that $\sigma$ is inversely proportional to $\lambda$. The preferable arrangement of precipitates is therefore such that the small precipitates are closely dispersed with each other.

Consequently, we revealed that the changes in the mechanical properties of $\mathrm{Fe}-\mathrm{Ni}$ based heat-resistant alloys during the annealing can be explained by the precipitation behaviors: (1) The drastic hardening in the initial stage of aging is due to the precipitation of $\mathrm{M}_{23} \mathrm{C}_{6}$ with high density, and (2) the gradual increase of hardness in the later stage of the aging is due to the additional precipitation of Laves phase.

These experimental results and discussion clearly indicates the importance of microstructure controls for improving the strength of the alloy, although additional mechanical tests under sever temperature and pressure conditions should be considered for practical use. The advancements in materials science and engineering research are thus needed to establish high-efficiency power plants.

\section{Conclusion}

We have discussed potentials of coal-fired power plants from the following viewpoints; (1) environmental conservation, (2) energy security, and (3) economic competitiveness. The coal has a big advantage of its unbiased reserve distribution, which enables stable procurement of the resource at a reasonable cost. Nevertheless, due to relatively large GHG emissions through coal combustion, further improvements in thermal efficiency of the power plants are vital. The key to achieve a high-efficiency coal-fired power plant is to develop a new heat-resistant alloy that can stand severe steam conditions in an advanced power plant over a long period. We have demonstrated that the mechanical properties of materials are strongly related to their microstructures through a materials science study on an Fe-Ni based heat-resistant alloy, in which the correlation between the hardness and the precipitation behaviors has been revealed. This result provides an important insight to enhance the mechanical property of the alloy through appropriate microstructure controls. The materials science and engineering study is also essential to suppress the introduction cost of a power plant, which is directly related to economic competitiveness of the power plants. Since across several decades, it is predicted that the coal consumption will continuously increase in non-OECD countries due to the increasing demands of electricity, there are business incentives to export high-efficiency power plants to those countries. In the medium-term energy strategy, active research and developments for improving the cost performance of the power plants is important both to reduce GHG emissions and to make the products more competitive.

\section{Acknowledgements}

The authors thank Nippon Steel $\&$ Sumitomo M etal for producing the alloys for the microscopy study. $H$. A. thank Dr. Shigeto Yamasaki (Kyushu University) for SEM observations and discussion. H. A. is grateful to Dr. M asatsugu Yaguchi and Dr. Kenji Kako (CRIEPI) for supports in TEM observations and helpful discussion. $H$. A. acknowledges the financial support from A dvanced Graduate Program in Global Strategy for Green A sia, Program for Leading Graduate Schools (Kyushu University).

\section{R eferences}

1) IPCC, Fifth Assessment Report: Climate Change 2013 (2013).

2) R. E. Dunlap and A. M. McCright, Environment: Science and Policy for Sustainable D evelopment, 

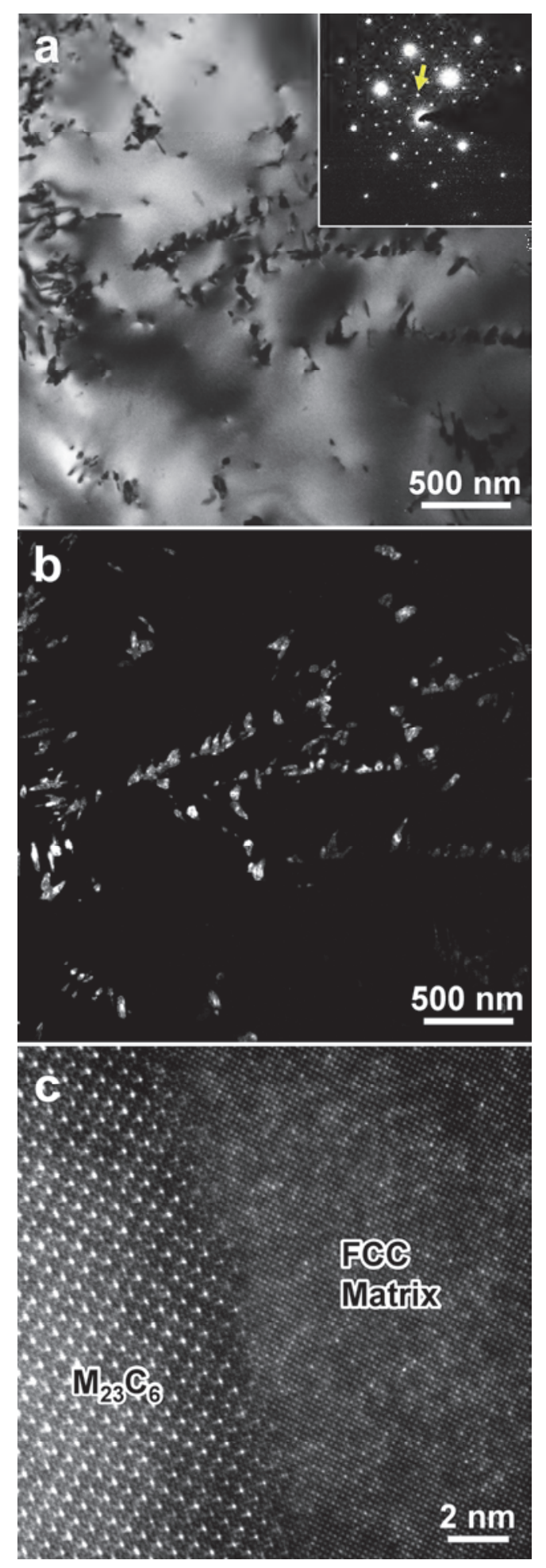

Fig. 6 (a) TEM bright field image, (b) dark field image, and (c) high-magnification scanning transmission electron microscope image of the specimen aged for $300 \mathrm{~h}$. Selected area diffraction pattern of the viewing region in (a) and (b) is shown as the inset in (a). The dark field image (b) is formed by using the reflection denoted by a yellow arrow in the diffraction pattern.
50:5, 26 (2010).

3) R. Knutti, J. Rogelj, J. Sedlacek and E. M. Fischer, Nat. G eosci., 9, 13 (2016).

4) R. Clémençon, J. Environment and D evelopment, 25, 3 (2016).

5) US Environmental Protection A gency (EPA), Carbon Pollution Standards for New, Modified and Reconstructed Power Plants, https://www.epa.gov /cleanpowerplan/carbon-pollution-standards-new-mo dified-and-reconstructed-power-plants.

6) M ETI, F eed-in Tariff Scheme in J apan (2012).

7) BP, BP Statistical Review of World Energy, bp.com/statistical review (2016).

8) T. C. Kinnaman, Ecological Economics, 70, 1243 (2011).

9) CRIEPI, CRIEPI News, 468, 1 (2010).

10) World Energy Council, Survey of Energy Resources 2010 (2010).

11) M ETI, Energy White Pater 2016 (2016).

12) The Federation of Electric Power Companies of Japan, FEPC INF OBASE 2016 (2016).

13) The Federation of Electric Power Companies of Japan, The current status of electric power industries (2013).

14) L. Zhang, J. Ruan and J. Ding, Applied Energy 136, 480 (2014).

15) Reuters, Severe coal shortage at Indian power plants hits industries (Oct 10, 2014).

16) B. Pokharel, Power shortage, its impacts and the hydropower sustainability assessment protocol: in the context of South Asia, NRSC 616 Project Paper (2011).

17)IEA, World Energy O utlook 2013 (2013).

18) IEA, World Energy O utlook 2008 (2008).

19) A-USC committee, Impact of development of A-USC technologies (2009).

20)METI, The G7 Ise-Shima Summit "Expanded Partnership for Q uality Infrastructure" (2016).

21) A gency for $N$ atural Resources and Energy, Points in the discussion on fossil-fuel power plants (2015).

22) The Federation of Electric Power Companies of Japan, Composition of electric power generation (2016). 
23)T. Takahashi, Developments of Fossil-Fuel Power Plants, The Nikkan Kogyo Shinbun, Tokyo (2012).

24) Electric Power Research Institute, U.S. Department of Energy and Ohio Coal Development Office Advanced UItra-Supercritical Materials Project for Boilers and Steam Turbines -Summary of Results (2011).

25) H. Semba, H. O kada, T. Hamaguchi, S. Ishikawa and M. Yoshizawa, Nippon Steel \& Sumitomo Metal Technical Report, 397, 71 (2013).

26) Y. Sawaragi, M. Igarashi, K. Okada and H. Semba, H eat-resistant M etals 123 Committee Report, 50, 331 (2009).

27) K. Okada, H. Semba, S. Ishikawa and M. Yoshizawa, CAM P-ISIJ , 25, 1192 (2012).

28) H. I. Aaronson, M. Enomoto and J. K. Lee, $M$ echanisms of $D$ iffusional $P$ hase Transformations in Metals and Alloys, CRC Press, New York (2010).

29) D. Hull and D. J. Bacon, Introduction to D islocations, Fifth edition, Butterworth-H einemann, Oxford (2011).

30)T. Maki, Microstructure Control in Steels, U chida Rokakuho, Tokyo (2015). 